\title{
Rhenium Re 186
}

National Cancer Institute

\section{Source}

National Cancer Institute. Rhenium Re 186. NCI Thesaurus. Code C1656.

A radioisotope with an atomic number of 75 and a half life of 90 hours that emits beta particles and gamma rays and is used in cancer treatment and diagnostic imaging technique. $(\mathrm{NCl})$ 